\title{
Gas Release and Transport Capacity Investment as Instruments to Foster Competition in Gas Markets
}

CORINNE CHATON, FARID GASMI,

MARIE-LAURE GUILLERMINET

AND JUAN-DANIEL OVIEDO 


\title{
Gas release and transport capacity investment as instruments to foster competition in gas markets*
}

\author{
Corinne CHATON
}

Laboratoire de Finance des Marchés d'Energie, France

Farid GASMI

Toulouse School of Economics (ARQADE \& IDEI), France

Marie-Laure GUILLERMINET

Hamburg University (FNU), Germany

Juan-Daniel OVIEDO

Universidad del Rosario, Colombia

\begin{abstract}
Motivated by recent policy events experienced by the European natural gas industry, this paper develops a simple model for analyzing the interaction between gas release and capacity investment programs as tools to improve the performance of imperfectly competitive markets. We consider a regional market in which a measure that has an incumbent release part of its gas to a marketer complements a program of investment in transport capacity dedicated to imports by the marketer, at a regulated transport charge, of competitively-priced gas. First, we examine the case where transport capacity is regulated while gas release is not, i.e., the volume of gas released is determined by the incumbent. We then analyze the effect of the "artificial" duopoly created by the regulator when the latter regulates both gas release and transport capacity. Finally, using information on the French industry, we calibrate the basic demand and cost elements of the model and perform some simulations of these two scenarios. Besides allowing us to analyze the economic properties of these scenarios, a policy implication that comes out of the empirical analysis is that, when combined with network expansion investments, gas-release measures applied under regulatory control are indeed effective short-term policies for promoting gas-to-gas competition.
\end{abstract}

JEL-code: L51, L95

Key words: Natural gas, Gas release, Regulation, Competition.

November 2010

\footnotetext{
${ }^{*}$ Corresponding author: farid.gasmi@tse-fr.eu. Parts of this material were presented at the Advanced Workshop in Regulation and Competition, Monterey, USA, July 2008, the International Conference on Policy Modeling, Berlin, Germany, July 2008, the European Economic Association Congress, Milan, Italy, August 2008, the International Energy Workshop, Stockholm, Sweden, June 2010, and the Association of Southern European Economic Theorists Meeting, Alicante, Spain, October 2010. We thank participants to these events for useful comments. All remaining errors are, however, only ours.
} 


\section{Introduction}

In 1998, the European Union launched a major liberalization reform of its gas industry which was compound of an oligopoly of public companies, such as the French GDF, semi-public companies, such as the Italian SNAM, and private companies, such as the Germans E.ON RUHRGAS and BEB. Prior to this reform, with the exception of the United Kingdom that initiated the liberalization of its energy sector in the 80s, national gas monopolies ensured gas supply through long-term contracts signed with major oil and gas companies from producing countries. This historical situation has made uneasy the introduction of upstream gas-to-gas competition in the EU Member countries. Indeed, to ensure that the opening of markets lead to well-functioning and effective competition, new entrants must not only have fair and efficient access to networks and consumers, but also to gas supply and flexibility services. The fact that the European gas market was almost entirely supplied through long-term contracts constituted a potential entry barrier to new actors, and hence a possible impediment to competition. With inadequate access to the gas commodity and lack of liquidity, spot markets couldn't be expected to develop smoothly.

To improve the situation, the European Commission has advocated the setting up of gas-release programs whereby incumbent operators sell a share of their gas supplied through long-term contracts, or even all of their long-term contracts (as in Italy), to potential competitors in order to encourage entry of new suppliers. These programs are meant to resolve short-term problems related to inadequate access to supply and/or capacity. Often suggested by governments, following the EC Directive 98/30, or by competition authorities, as a condition for approving mergers involving the incumbent, the implementation of these short-term measures in major European countries has been generally justified on two grounds. First, by bringing in gas-to-gas competition, these gas-release programs were expected to affect in a significant way the industry's market structure that was typically organized under a vertically integrated form. ${ }^{1}$ This

\footnotetext{
${ }^{1}$ We are assuming here that when a firm signs a long-term contract with a gas-producing foreign country, from the perspective of the home country's market, it is as if it controls production.
} 
was the case in France, Spain, Italy, and the United Kingdom. Second, these programs were viewed as corrective measures following the creation through concentration of a dominant operator at a national level. This was for example the case in Austria and Germany. Applied in European countries during a period ranging from 2 to 10 years, these measures involved an average of about 2 to $3 \%$ of total supply in a single country.

Despite the large popularity of gas-release programs as a means of bringing competition into the natural gas industry, the academic literature that analyzes their economic impact is strikingly thin. ${ }^{2}$ For the purpose of this paper, we should mention Chaton et al. (2008) who focus on gas release as a regulatory instrument and Clastres and David (2009) who examine the behavior of an incumbent subject to asymmetric regulation of the gas-release measures type discussed above. Also, concerned with the liberalization of European gas markets, Cremer and Laffont (2002), Cremer et al. (2003), Gasmi et al. (2005), Gasmi and Oviedo $(2005,2010)$ focus on transport capacity as the sole instrument used to enhance competition and security of supply. ${ }^{3}$ While these papers are concerned with the important policy objective of promoting competition in the natural gas industry, they exclusively consider gas release or capacity investment as regulatory instruments. This paper analyzes the efficiency of these two instruments when the regulator may use them simultaneously. It also seeks to highlight the mechanism through which these two instruments interplay.

The plan of this paper is as follows. The next section describes some representative European experiences with gas-release programs. Section 3 presents the basic ingredients of our theoretical model in which gas release and transport capacity are instruments that can be used by the regulator to foster competition. While transport capacity is always assumed to be a regulated activity, section 4 considers the scenario where the decision of how much gas to release is under the control of/decentralized to the incumbent gas supplier. Section 5 considers then the scenario where the gas-release and investment activities are

\footnotetext{
${ }^{2}$ In contrast, there exists a large institutional literature on the subject that has essentially come out of the European Union.

${ }^{3}$ We should also mention the work of Sannarnes (2007) which is concerned with investment mechanisms as tools to optimally design the transport capacity network.
} 
both regulated. Section 6 presents and discusses the results of some calibration and simulation exercises aimed at comparing the optimal policies under the two scenarios. Section 7 summarizes the main arguments and findings of the paper and points to some directions for further research.

\section{European gas-release experiences}

In Europe, gas-release programs have often been appended to a set of regulatory measures of an asymmetric nature aimed at reducing the market share of the incumbent. This type of regulation was first implemented in the UK in 1992 with the objective of reducing the $60 \%$ market share possessed by British Gas (BG) in the industrial and commercial segment between 1992 and 1995. Since then, it has been adopted elsewhere as an instrument to facilitate the introduction of competition. In Spain, since January 1, 2003, the law requires that the supply of any single operator do not represent more than $70 \%$ of the total consumption in the country. In Italy, the Decree No. 164/2000 stipulates that during the period running from January 1, 2003 to December 31, 2010 the sales to final consumers of any single operator cannot be more than $50 \%$ of the annual domestic gas consumption. Moreover, since January 1, 2002, no single operator can inject into the transport network a volume representing more than $75 \%$ of annual gas consumption, this percentage annually decreasing by $2 \%$ to reach $61 \%$ by December 31, 2010 .

While the lessons to be drawn from the introduction of gas-release programs in Europe are mixed, these experiences highlight the importance of the design of the auction mechanisms through which the programs are implemented, in particular, the process by which price, quantity, and duration are determined. Gas release has certainly gained in interest following the success of the UK program. According to the organizers of these programs and the authorities in charge of competition, the UK program has substantially contributed to the development of gas-to-gas competition prior to October 1998 when new transport capacity was deployed. ${ }^{4}$ This program has also strengthened measures aimed at decreas-

\footnotetext{
${ }^{4}$ The NBP spot market has indeed developed rapidly over the period during which the asymmetric regulation was implemented. This period was followed by the commissioning
} 
ing market power in the sector such as the $90 / 10$ rule that had BG commit to contract for no more than $90 \%$ of the volume of the new fields in the North sea, leaving up to $10 \%$ of this volume to other firms.

In the UK, the volumes of gas released were allocated proportionally to the number of participating suppliers which were about 32 in the first year and 102 in the second. In Spain, after being auditioned by the Ministry of Economy, potential participants to the gas-release program were selected on the basis of their commitment to contribute to efforts to liberalize the Spanish gas market and to stimulate competition in this sector in the short, medium, and long term. The volumes were then allocated according to the order book. The quantities were allocated through negotiations among partners in Italy, auctions in Germany and Austria, and both auctions and over-the-counter contracts in France.

The Spanish government conducted a gas-release program for $25 \%$ of gas imports from Algeria that started in October 2001 and ended on January 1, 2004. Then, the contracts were turned over to GAS NATURAL/ENAGAS. The total retrocession amounted to 48.76 Terawatt-hours (TWh) per Gross Calorific Value (GCV) representing 11\% of total supplies to the Spanish market and 15\% of the eligible market. Participation to the auctions was made conditional on submission of sales forecasts and plans to secure diversified gas supplies once the gas-release program had come to an end. The average price was set equal to the gas purchasing cost, i.e., the oil-indexed price of gas, to which a fixed management fee is added. Overall, however, this gas-release program had only a modest impact in comparison with the substantial increase of natural gas demand and the lowering of the eligibility threshold.

In Italy, starting in January 2002 and until December 2010, the incumbent operator SNAM/ENI had to release $39 \%$ of its gas contracted out under long-term conditions. This gas-release program was combined with additional measures to reduce individual firms' market shares. So, for example, no operator could sell gas, through its parent companies or its subsidiaries, to customers

of the Interconnector pipe which is a sub-sea gas pipeline linking the UK with continental Europe. This pipeline provided a strategic bi-directional link between the UK and Continental European energy markets. 
whose consumption represented more than $50 \%$ of the annual domestic gas net (of won) consumption. These measures that imposed quotas on imports and sales were often bypassed by SNAM/ENI. ${ }^{5}$ This gas-release program has essentially benefited the power companies ENEL and EDISON. In 2004, the Italian regulatory and competition authorities unveiled an abuse of dominant position by ENI that led these authorities to set a program whereby ENI would release 105.8 TWh of gas per year during the period 2004-2008.

The German gas-release program was launched in July 2003 and the first deliveries went through in October of the same year. As a condition for the approval of the merger of E.ON and RUHRGAS, the German government obtained a commitment from E.ON RUHRGAS to release 213.9 TWh of gas in six annual auctions on the first of October, amounting to an average of 35.65 TWh available monthly through auctions over a three-year period. The German system of retrocession is a biding mechanism with a reserve price equal to $95 \%$ of the imported gas price. At the first auction, the gas was sold in the form of 33 lots and no participant could buy more than 11 lots. However, more than half of the lots had no takers. The market experienced a low participation rate because of poor transportation conditions, a high minimum bid, and important asymmetric information between E.ON RUHRGAS and the regulator on various dimensions of supply. E.ON RUHRGAS has benefited from an annuity on the gas-release program.

To counter the potential adverse effect on gas-to-gas competition stimulation of the German experience and following an agreement between the Ministry and E.ON RUHRGAS to meet after the first bid to discuss possible modifications, amendments were made to the auction mechanism. These changes took into consideration the auction participants' requests mainly related to the minimum bid level (participants could evaluate in advance the price and hedge against price risk), the contractual daily requirement (the volume the seller/buyer agrees to deliver/take at the delivery point during the delivery period), and the volume obligation guaranteed by the auction (reduced by $50 \%$ ).

As a condition for the approval of the merger of OMV and the gas activities

${ }^{5}$ For example, ENI had invested in combined cycle gas turbine technology and had minimized the quantities of gas it had to release. 
of ENERGIE ALLIANZ that led to the creation of ECONGAS, the Austrian competition authority launched a gas-release program in 2002. In July 2003, ECONGAS auctioned off $2.86 \mathrm{TWh}$ of natural gas. ECONGAS held its second online auction for the same volume of gas in July 2004 and its third for a volume of 3.11 TWh in July 2005. An important aspect of the Austrian gas regulatory policy is that, although the incumbent has to release $20 \%$ of its gas imported through long-term contracts until 2008, the price of the released gas is determined solely by the auction and ECONGAS has no obligation to sell if such a price is below cost. While this gas-release program has counterbalanced to some extent the impact of the creation of ECONGAS and has contributed to the development of the Baumgarten hub, it has not really stimulated gas-to-gas competition.

Despite the mitigated experiences of gas-release programs, such measures have occupied the European scene. On September 20, 2006, SUEZ and Gaz de France (GDF) offered the European Commission to take part in a gas-release program in France and Belgium in return to their merging. On November 14, 2006, the EC decided not to impose the program. In Denmark, as part of the reorganization of the gas sector previously under the monopoly of the incumbent DONG ENERGY for the purchase of domestic production, the Danish competition authority and the EC requested that this company cess buying gas from the DUC, the sole Danish producer, as long as the latter hasn't sold 77 TWh to alternative operators. The period covered by this program runs from 2005 to 2010.

As in the case of the British program, the French experience suggests that, although widely used, gas release is mainly a transitory instrument to enhance competition in gas markets. Concerned with limited competition in France, in particular, in the Southern part of the country, the French energy regulator, the Commission de Régulation de l'Energie (CRE), has approved the gas-release program proposed by GDF and TOTAL at the time the transportation network had to be restructured in 2004. This 3-year program started in January 2005. During this period, GDF pledged to sell 15 TWh per year through auctions and over-the-counter contracts and TOTAL to make available $1.1 \mathrm{TWh}$ per 
year through auctions. Although the released volume only represented 3.5\% of the sales of GDF and the regional operator GAZ DU SUD OUEST, the CRE has argued that these temporary supplies should allow new marketers to enter the Southern market where the current situation is simply "... no competition." Moreover, the CRE trusted that by the first half of 2009 the latest, new infrastructures, such as the second liquefied natural gas terminal, the Fos-2 LNG terminal, and that, by the beginning of 2009, more pipeline interconnection points with the Spanish transport network should enable these new entrants to secure their own longer-term supplies. ${ }^{6}$

The totality of the quantities offered were sold (CRE, 2006). Sixteen companies have participated in auctions held by GDF and 12 lots representing a total of $6 \mathrm{TWh}$ were sold. These lots were acquired by the Belgium-based subsidiary of the Italian ENI, DISTRIGAS, the Spanish GAS NATURAL, and the French TOTAL. In addition, GDF has sold 9 TWh over the counter to the British BP, DISTRIGAS, GAS NATURAL, and the French power company EDF. Eight companies have participated in the auctioning of 1.1 TWh in 10 lots by TOTAL. Only 5 of the 10 lots, representing a total of $0.55 \mathrm{TWh}$, were acquired by EDF and the Spanish power company IBERDROLA at the reserve price set by TOTAL. The remaining $0.55 \mathrm{TWh}$ were sold over the counter by TOTAL to DISTIGAS. A year after its launching, the French gas-release program has allowed three foreign suppliers to compete with the incumbents in the southern French market. Nevertheless, the CRE considers that competition is still too limited (CRE, 2006).

On November 22, 2007, the CRE has published its analysis of the gas-release program following the public hearing launched on July 10 of the same year. The gas-release program has been the main supply of gas from diversified sources in the south and the southwest regions of France. However, the upstream segment of the French industry (imports and production) has not changed much. Besides the fact that GDF and TOTAL hold the major part of entry capacity, in 2006, $88 \%$ of imported gas in France was done by GDF and $6 \%$ by TOTAL. The CRE reports that $57 \%$ of the gas-release volume in the south and $92 \%$ in the

\footnotetext{
${ }^{6}$ The Fos-2 LNG terminal opened on June 23, 2009.
} 
southwest have been marketed to final customers. Purchasers of this gas have resold the residual volumes in the wholesale market or at the French border either because of difficulties to compete with incumbents in the French retail market or to benefit from high prices in the northern European markets.

Since the introduction of the gas-release measures, the size of the French market, opened to competition on July 1, 2007 has increased by about 40 to $50 \%$, from 370 to $520 \mathrm{TWh}$ per year. The CRE considers that in the medium term, the development of new infrastructures will not fully compensate the loss of volumes sold under the gas-release program in the south and southwest regions. To maintain a sufficient level of competition and ensure the continuity of supply from alternative sources, the CRE seeks to establish new gas release measures on January 1, 2009 when some lots come to expiration. Given the increase in the size of the market for eligible customers, the programs represent at least $15 \%$ of consumption in both regions, which now represents about 21 TWh per year for the southern zone (essentially supplied by GDF-SUEZ) and 6 TWh per year for the southwest (supplied by GDF-SUEZ and TOTAL).

The CRE finds it necessary to adjust the programs so that there are regular allowances (at least once a year), the duration of the portfolio of contracts is extended from 1 to 3 years, and the anonymity of the participants to the programs is respected. However, in order to determine whether or not further gas-release programs need to be implemented in France as the CRE recommended, the evaluation of the market power of GDF-SUEZ and TOTAL, taking account of current and future network capacities, ought to be updated. Indeed, since the 2007 evaluation, GDF-SUEZ has committed to reduce its long-term import capacities. $^{7}$

\footnotetext{
${ }^{7}$ Following an antitrust case filled by the EC in May 2008 against GDF-SUEZ, this operator has made some commitments that are currently under debate. The EC argues that "..these commitments could have a major structural impact on the ability of alternative operators to enter the French market for the benefit of both residential and industrial gas consumers." (see http://europa.eu/rapid/pressReleasesAction and http://europa.eu/competition/antitrust/cases/decisions/39316/proposed_commitments.pdf)
} 


\section{Basic ingredients of the model}

This section presents the basic ingredients of a simple model that we use to analyze gas-release and capacity-investment policies. Consider a regional gas market, market $M$, dominated by an incumbent firm (firm $I$ ) that buys gas from producers through long-term contracts. Let $p(\cdot)$ represent the market inverse demand function, $C_{I}(\cdot)$ the incumbent's variable cost function, and $F_{I}$ its fixed cost. Under this monopolistic market structure the incumbent's profit function is $\Pi_{I}=p\left(q_{m}\right) \times q_{m}-C_{I}\left(q_{m}\right)-F_{I}$ where $q_{m}$ is quantity of gas sold in the market. This profit-maximizing incumbent firm exercises then its market power according to the standard inverse-elasticity rule $\left(p-C_{I}^{\prime}\right) / p=1 / \varepsilon{ }^{8}$

To stimulate competition in this regional gas market, a regulator may give incentives to a transporter (firm $T$ ) to invest in pipelines that will allow imports of gas from a competitive market, market $C .{ }^{9}$ Clearly though, building new pipelines can only be a middle- to long-term objective. Meanwhile, in order to improve the efficiency of this regional market, the regulator can create an "artificial" duopoly by requiring that the regional monopolist sell or release to a marketer (firm $R$ ) a fraction, $\alpha$ say, of its supply through long-term contracts at a unit price $p_{R}$.

These two measures, namely, capacity investment and gas release, may coexist. Indeed, the regulator has the opportunity to introduce competition by complementing the gas-release program with investments in transport capacity $K$ dedicated to imports of natural gas acquired under competitive conditions in market $C$. Under these circumstances, the gas supplied by the marketer comes from two alternative sources and is composed of gas released by the incumbent at a cost $p_{R}$, in volume $q_{R}$, and gas imported from market $C$, in volume $K$, at a cost $\left(c+p_{K}\right)$, where $c$ is the competitive price of shipped gas and $p_{K}$ is the regulated transport charge of this gas. ${ }^{10}$

The total quantity sold in market $M, q_{m}$, is thus composed of the gas di-

${ }^{8}$ As an illustration, assuming the functional forms $p\left(q_{m}\right)=\gamma-q_{m}, C_{I}\left(q_{m}\right)=\theta q_{m}, \gamma>\theta$ that will be used later, this rule yields $q_{m}=(\gamma-\theta) / 2$ and $\Pi_{I}=(\gamma-\theta)^{2} / 4-F_{m}$, requiring $F_{I} \leq(\gamma-\theta)^{2} / 4$ for the firm's profits to be nonnegative.

${ }^{9}$ Market $C$ might represent a competitive production area or a spot market.

${ }^{10}$ This transport charge is meant to represent the Third Party Access (TPA) charge. 
rectly supplied to the final consumers by the incumbent, $q_{I}$, the gas provided by the marketer which is gas released by the incumbent, $q_{R}$, and the gas directly provided by the marketer through imports, $K$. These volumes satisfy the following identities:

$$
\begin{gathered}
q_{m}=q_{I}+q_{R}+K \\
q_{R}=\alpha\left(q_{m}-K\right) \\
q_{I}=(1-\alpha)\left(q_{m}-K\right)
\end{gathered}
$$

We assume that the incumbent's variable cost $C_{I}(\cdot)$ is separable into the cost of gas dedicated to final consumption, $C_{I}^{I}(\cdot)$ and the cost of gas released to the marketer, $C_{I}^{R}(\cdot) .{ }^{11}$ Under this duopolistic market structure, the incumbent's profit function is thus given by

$$
\Pi_{I}=p\left(q_{I}+q_{R}+K\right) q_{I}+p_{R} q_{R}-C_{I}^{I}\left(q_{I}\right)-C_{I}^{R}\left(q_{R}\right)-F_{I}
$$

The profit function of the marketer is given by

$$
\Pi_{R}=p\left(q_{I}+q_{R}+K\right)\left(q_{R}+K\right)-p_{R} q_{R}-\left(c+p_{K}\right) K
$$

and that of the regulated transporter by

$$
\Pi_{T}=p_{K} K-C_{T}(K)-F_{T}
$$

where $C_{T}(K)$ is the variable cost of the transporter and $F_{T}$ its fixed cost. ${ }^{12}$ Finally, the net consumers surplus CS is given by

$$
\mathrm{CS}=S\left(q_{I}+q_{R}+K\right)-p\left(q_{I}+q_{R}+K\right)\left(q_{I}+q_{R}+K\right)
$$

where $S(\cdot)$ represents gross consumer surplus, and social welfare W is expressed as the unweighed sum of $\Pi_{I}, \Pi_{R}, \Pi_{T}$, and CS given in (4)-(7).

\footnotetext{
${ }^{11}$ This separability assumption about the firm's technology may be justified by the fact that the incumbent has the possibility to renegotiate its long-term contracts. We also assume that the incumbent's cost function of gas dedicated to final consumption is increasing convex and twice continuously differentiable with $C_{I}^{I^{\prime \prime \prime}}=0$. As to the incumbent's cost function of gas released to the marketer, $C_{I}^{R}$, it is merely assumed to be increasing convex.

${ }^{12}$ In this paper, the transport access charge $p_{K}$ is assumed to be exogenous. This charge might reflect the long-run marginal cost of the whole transport network and not only that of its regional portion considered here.
} 


\section{Unregulated gas release and regulated capacity}

As a preliminary step, let us assume that the gas-release activity is not regulated while investment in transport capacity is. ${ }^{13}$ We assume the following sequence of events. First, the regulator sets capacity $K$, then the incumbent sets the gas-release charge $p_{R}$, and finally the incumbent and the marketer compete à la Cournot in $q_{I}$ and $q_{R} \cdot{ }^{14}$ Solving backward, we first consider the output determination game in which the incumbent maximizes its profit given in (4) with respect to $q_{I}$, while the marketer maximizes its profit given in (5) with respect to $q_{R}$. The first-order conditions of this Cournot game are

$$
\begin{gathered}
\frac{\partial \Pi_{I}}{\partial q_{I}}=p+q_{I} p^{\prime}-C_{I}^{I^{\prime}}\left(q_{I}\right)=0 \\
\frac{\partial \Pi_{R}}{\partial q_{R}}=p+\left(q_{R}+K\right) p^{\prime}-p_{R}=0
\end{gathered}
$$

These conditions implicitly define a couple of output functions that depend on the gas-release charge and capacity, $\widetilde{q}_{I}\left(p_{R}, K\right)$ and $\widetilde{q}_{R}\left(p_{R}, K\right)$. Before proceeding on to solve the next stages, we give a lemma that provides us with useful expressions for the slopes of these supply functions. ${ }^{15}$

Lemma 1. The supply functions $\widetilde{q}_{I}\left(p_{R}, K\right)$ and $\widetilde{q}_{R}\left(p_{R}, K\right)$ satisfy

$$
\begin{aligned}
\frac{d \widetilde{q}_{I}}{d p_{R}} & =-\frac{1}{3 p^{\prime}-2 C_{I}^{I^{\prime \prime}}} & \frac{d^{2} \widetilde{q}_{I}}{d p_{R}^{2}} & =\frac{2 C_{I}^{I^{\prime \prime \prime}}}{3 p^{\prime}-2 C_{I}^{I^{\prime \prime}}}\left[\frac{d \widetilde{q}_{I}}{d p_{R}}\right]^{2}=0 \\
\frac{d \widetilde{q}_{R}}{d p_{R}} & =\frac{2 p^{\prime}-C_{I}^{I^{\prime \prime}}}{p^{\prime}\left[3 p^{\prime}-2 C_{I}^{I^{\prime \prime}}\right]} & \frac{d^{2} \widetilde{q}_{R}}{d p_{R}^{2}} & =-\frac{C_{I}^{I^{\prime \prime \prime}}}{3 p^{\prime}-2 C_{I}^{I^{\prime \prime}}}\left[\frac{d \widetilde{q}_{I}}{d p_{R}}\right]^{2}=0 \\
\frac{d \widetilde{q}_{I}}{d K} & =0 & \frac{d \widetilde{q}_{R}}{d K} & =-1
\end{aligned}
$$

\footnotetext{
${ }^{13}$ This scenario might be seen as representing the 2005-2008 period during which, in France, GDF volunteered to pledge to auction-off gas (see section 2).

${ }^{14}$ Recall that investments in capacity are dedicated to the marketer.

${ }^{15}$ The proof of this lemma involves standard calculus and is available from the authors upon request. However, it is worth mentioning here that existence and uniqueness of equilibrium is guaranteed by our assumptions about demand and incumbent's technology. In fact, it corresponds to the crossing point of the firms' reaction functions derived from (8) and (9).
} 
This lemma says that, in equilibrium, an increase in the gas-release charge $p_{R}$ leads to an increase in the incumbent's output $q_{I}$ and a decrease in the marketer's output $q_{R}$ with a net negative effect on aggregate output. ${ }^{16}$

Next, these supply functions $\widetilde{q}_{I}\left(p_{R}, K\right)$ and $\widetilde{q}_{R}\left(p_{R}, K\right)$ are substituted back into the incumbent profit function given in (4) to express it as a function of $p_{R}$ and $K, \widetilde{\Pi}_{I}\left(p_{R}, K\right)$. The second stage of the backward resolution algorithm consists then in maximizing this "reduced form" profit function with respect to $p_{R}$, yielding the following first-order condition:

$$
\frac{\partial \widetilde{\Pi}_{I}\left(p_{R}, K\right)}{\partial p_{R}}=\widetilde{q}_{I}+2 \widetilde{q}_{R}+\frac{p_{R}-C_{I}^{R^{\prime}}}{p^{\prime}}-\frac{\left(p-C_{I}^{I^{\prime}}\right)-\left(p_{R}-C_{I}^{R^{\prime}}\right)}{3 p^{\prime}-2 C_{I}^{I^{\prime \prime}}}=0
$$

The end result of this profit-maximization problem is a gas-release charge $p_{R}$ as a function of capacity $K, \widehat{p}_{R}(K)$. The next lemma provides some information on how capacity affects the release charge.

Lemma 2. The equilibrium release-charge function $\widehat{p}_{R}(K)$ satisfies

$$
\frac{d \widehat{p}_{R}}{d K}=\frac{p^{\prime}\left(3 p^{\prime}-2 C_{I}^{I^{\prime \prime}}\right)}{\left(2 p^{\prime}-C_{I}^{I^{\prime \prime}}\right)}-C_{I}^{R^{\prime \prime}}
$$

This lemma says that, in equilibrium, an increase in transport capacity $K$ leads to a strict decrease in the gas-release charge $p_{R}$ which, by the results established in Lemma 1, implies an unambiguous expansion of aggregate output. Thus, investment in transport capacity appears to be an effective pro-competitive measure as stated in the following proposition:

Proposition 1. When gas release is not regulated, investment in capacity is pro-competitive.

The third and final stage of the backward resolution algorithm requires substituting the functions obtained in Lemmas 1 and 2 into the social welfare function to obtain

\footnotetext{
${ }^{16}$ This implication corresponds to the general result in Industrial Organization saying that with strategic substitutes and a unique Cournot-Nash equilibrium, a firm's output decreases with its marginal cost and increases with its competitor's (Tirole, 1988, p. 220). Moreover, we find that an increase in a firm's marginal cost decreases industry output.
} 


$$
\begin{gathered}
\mathrm{W}(K)=S\left(\widetilde{q}_{I}\left(p_{R}, K\right)+\widetilde{q}_{R}\left(p_{R}, K\right)+K\right)-C_{I}^{I}\left(\widetilde{q}_{I}\left(p_{R}, K\right)\right)-C_{I}^{R}\left(\widetilde{q}_{R}\left(p_{R}, K\right)\right) \\
-c K-C_{T}(K)-F_{I}-F_{T}
\end{gathered}
$$

To find the optimal level of capacity, social welfare is then maximized with respect to $K$ subject to the profit-maximization constraint of the incumbent with respect to $p_{R}$, given in (10), and the transporter's participation constraint and the incumbent's output nonnegativity constraint respectively given by

$$
\Pi_{T}=p_{K} K-C_{T}(K)-F_{T} \geq 0
$$

and

$$
q_{I} \geq 0
$$

Letting $\eta_{R}$ and $\phi_{T}$ respectively denote the Lagrange multipliers associated with the incumbent's profit-maximization constraint and the transporter's participation constraint and taking into consideration the results of Lemmas 1 and 2 in the respective set of first-order conditions, the next proposition provides a condition that capacity has to satisfy when gas release is unregulated.

Proposition 2. When transport capacity is regulated and the decision about how much gas to release is left to a profit-maximizing incumbent, letting $\eta_{R}$ and $\phi_{T}$ respectively denote the Lagrange multipliers associated with the incumbent's profit-maximization constraint and the transporter's participation constraint, the following condition characterizes transport capacity:

$$
\left[c+C_{T}^{\prime}(K)\right]-\phi_{T}\left[p_{K}-C_{T}^{\prime}(K)\right]=C_{I}^{R^{\prime}}+\eta_{R}
$$

Proposition 2 says that when transport capacity is regulated but gas release is not, capacity is built up to the point where the net social marginal cost of bringing gas from the competitive market arising from the marginal cost of imported gas, $\left[c+C_{T}^{\prime}(K)\right]$, adjusted for the social marginal benefit associated with the mark-up over the extra unit of imported gas relaxing the transporter's participation constraint, $\phi_{T}\left[p_{K}-C_{T}^{\prime}(K)\right]$, equates the "distorted" social marginal cost of released gas stemming from the marginal cost of one unit of gas released 
by the incumbent, $C_{I}^{R^{\prime}}$, augmented by the marginal contribution of that gas unit to the incumbent's profit-maximization constraint, $\eta_{R}$.

\section{$5 \quad$ Regulated gas release and capacity}

When gas release is also regulated, the timing is as follows. First, the regulator sets capacity $K$ and the gas-release charge $p_{R}$. Then, the incumbent and the marketer compete à la Cournot. Again, solving backward, we first find the supply functions $\widetilde{q}_{I}\left(p_{R}, K\right)$ and $\widetilde{q}_{R}\left(p_{R}, K\right)$ from the first-order conditions (8) and (9). ${ }^{17}$ Then, we substitute these functions back into the social welfare function to obtain (12).

Note that, since gas release is regulated, the regulator has now to ensure that the incumbent is willing to participate. Assuming that accounting separation is imposed, the following constraint thus needs to be taken into account:

$$
p_{R} q_{R}-C_{I}^{R}\left(q_{R}\right) \geq 0
$$

Social welfare given by (12) is then maximized with respect to $p_{R}$ and $K$ subject to the transporter and incumbent participation constraints, and the incumbent's output nonnegativity constraint. The next proposition establishes a condition that characterizes transport capacity when both capacity and gas release are regulated.

Proposition 3. When transport capacity and gas release are regulated, letting $\phi_{R}$ and $\phi_{T}$ respectively denote the Lagrange multipliers associated with the incumbent's and the transporter's participation constraints, capacity has to satisfy

$$
\left[c+C_{T}^{\prime}(K)\right]-\phi_{T}\left[p_{K}-C_{T}^{\prime}(K)\right]=C_{I}^{R^{\prime}}-\phi_{R}\left[p_{R}-C_{I}^{R^{\prime}}\right]
$$

Proposition 3 says that when both transport capacity and gas release are under the control of the regulator, capacity is built up to the point where the net social marginal cost of bringing gas from the competitive market arising from the marginal cost of imported gas, $\left[c+C_{T}^{\prime}(K)\right]$, adjusted for the social marginal benefit associated with the mark-up over the extra unit of imported

\footnotetext{
${ }^{17}$ Note that these supply function satisfy Lemma 1.
} 
gas relaxing the transporter's participation constraint, $\phi_{T}\left[p_{K}-C_{T}^{\prime}(K)\right]$, equates the net social marginal cost of releasing gas from the incumbent, $C_{I}^{R^{\prime}}$, adjusted by the social marginal benefit associated with the mark-up over that release-gas unit relaxing the incumbent's participation constraint, $\phi_{R}\left[p_{R}-C_{I}^{R^{\prime}}\right]$.

\section{The artificial duopoly effect}

This section seeks to compare the two scenarios discussed in the previous sections on the basis of social welfare. What makes such an exercise worthwhile doing though? Recall that both scenarios assume that transport capacity is regulated and the first scenario, designated by $S_{1}$ hereafter, assumes that gas release is not regulated while the second scenario, noted $S_{2}$ hereafter, assumes it is. Intuition suggests that, as the regulatory schemes considered under these two scenarios are analyzed under complete information, the principle of optimality should yield a higher social welfare level under the scenario that allows for an extra regulatory instrument, namely, $S_{2}$. However, the fact that the downstream duopoly, the equilibrium outcome of which the regulator has to account for when determining the optimal capacity investment policy, is, in some sense, "artificial" raises questions about this result.

To be more specific, our empirical exercise here finds its justification in the presumption that this whole issue boils down to the question of how the extra regulatory instrument and the artificial duopoly effects on social welfare aggregate. ${ }^{18}$ Given these theoretical difficulties and in view of the importance of gas-release measures from a policy standpoint, we attempt to bring in some quantitative evidence on how these two effects are reflected in social welfare by conducting an empirical analysis of scenarios $S_{1}$ and $S_{2}$. First, we specify some functional forms for the basic functions of our theoretical model and calibrate them using French data (section 6.1). Then, we perform some simulations of the scenarios and draw some comparisons (section 6.2). ${ }^{19}$

\footnotetext{
${ }^{18}$ Note that we are assuming here that the fact that the duopoly is artificial, in the sense that is defined in the paper, should affect the economic welfare impact of the standard duopoly externality due to the fact that some of a firm's profit increases is achieved at the expense of the other firm's profit decreases.

${ }^{19}$ Note that the simulations also allow us to check the internal coherence of the scenarios.
} 


\subsection{Calibration}

The first function that is needed in order to perform simulations is the inverse demand function for natural gas. We assume the linear form $p\left(q_{m}\right)=\gamma-\alpha q_{m}$, $\alpha, \gamma>0$. Ideally, one would use time-series or cross-sectional data to estimate the two parameters of this linear demand function. However, given the scarcity of data and the relatively recent history of the gas industry reforms, we impose the value of 1 for $\alpha$ and draw on existing econometric demand studies to calibrate the demand intercept $\gamma$.

Since the mid-70s a large econometric literature has developed following the need to save energy and to target the objectives of energy policies. However, although this literature has examined demand for various energy sources in both the residential and industrial sectors, it is mainly concerned with household demand for electricity and to a lesser extent for natural gas. ${ }^{20}$

Krichene (2005) has found that in recent years demand for natural gas has substantially varied and price-elasticity has dropped markedly after 1974. Based on the more recent surveys by Dahl (2004) and Liu (2004), we take for the priceelasticity of demand of gas in France the figure 0.56. Given this value of the elasticity, we calculate a value for the intercept of the inverse demand function, $\gamma$, corresponding to an average level of the British price, €6.522/million BTU, amounting to $€ 22.25 / \mathrm{MWh} .^{21}$ The value found for the intercept term is then 62. The wholesale price being equal to $€ 3 / \mathrm{MWh}$, we take the price in the competitive sector, $c$, to be equal to $€ 29 / \mathrm{MWh}$.

Let us now turn to the calibration of the gas commodity cost function. For this function, we assume the form $C_{I}\left(q_{I}+q_{R}\right)=C_{I}^{I}\left(q_{I}\right)+C_{I}^{R}\left(q_{R}\right)+F_{I}=$ $\theta_{I} q_{I}+\theta_{R} q_{R}+F_{I}$. As the spot market is not well developed yet, it seems reasonable to assume that the incumbent obtains gas solely through long-term contracts. Hence, $\theta_{I} q_{I}$ can be seen as the variable cost of purchasing gas trough long-term contracts plus the transport cost of this gas from the source to the French border. The parameter $\theta_{I}$ can then be seen as the border price of gas

\footnotetext{
${ }^{20}$ For a review of this literature, see Bohi and Zimmerman (1984). Madlener (1996) reviews the literature concerned with European markets.

${ }^{21}$ In contrast to France, where regulated prices for final consumers still exist, the UK rates reflect market prices.
} 
paid by GDF. We also distinguish between the price paid by this historical operator for gas to sell to final consumers, $\theta_{I}$, from that to make available to the entrant (the marketer), $\theta_{R}{ }^{22}$

We have used as a value of $\theta_{I}$ the average border price corresponding to the long-term contracts binding GDF with Algeria, Norway, and Russia. These prices have changed over time (CRE, 2008). In late September 2008, prices of gas supplied through long-term contracts which are relevant to our base case amounted to $€ 27.95 / \mathrm{MWh}$ for Russian gas that entered Germany via Waidhaus, $€ 29.45$ /MWh for Algerian gas that entered France via the Montoir-de-Bretagne terminal, and $€ 30.25 / \mathrm{MWh}$ for Norwegian gas that entered Germany via the Emden terminal. Stable since April 2006, prices of long-term contracts had risen by about $22 \%$ in the second quarter of 2008 and $15 \%$ in the third quarter of 2008 before stabilizing at a level never seen before. DGEC-IFP (2008) estimates the average border price in Europe in October 2008 to $€ 40 / \mathrm{MWh}$, about $15 \%$ above that of the previous month of the same year. DGEC-IFP (2009) shows that this border price is slightly below $€ 45 / \mathrm{MWh}$ in November before starting to decline.

On the basis of these information, we assume that $\theta_{I}$ and $\theta_{R}$ lie somewhere between $€ 15$ and $€ 55 / \mathrm{MWh}$. For simplicity, we assume that $F_{I}$ represents the transport cost of gas from the border to the final consumer, i.e., the access charge to the international transport network, and is included in the border price of gas. For simulation purposes, we assume an initial value of $\theta_{R}$ equal to $€ 38.18 / \mathrm{MWh}$ and take $\Delta \equiv\left(\theta_{I}-\theta_{R}\right)$, such that $\Delta \in(7.02,14.46) .{ }^{23}$

Turning to transport technology, it is worth noting that the transport capacity between the producer and the incumbent is closely tied to the existing long-term contracts. Consequently, without new investments in transport infrastructure an entrant wouldn't have access to the same sources of gas as the

\footnotetext{
${ }^{22}$ Note that the discrepancy between these two prices should depend on the relative bargaining power of the operator and the gas suppliers.

${ }^{23} \mathrm{~A}$ couple of remarks are worth making. First, note that the assumed values are such that $\theta_{R}>c$, i.e., that there is an efficiency gap between the gas release and the competitive technologies. Second, the condition $\Delta\left(=\theta_{I}-\theta_{R}\right)>0$ may reflect a situation under which gas currently contracted under long-term conditions or produced locally is more costly than it was negotiated or extracted in the past. Thus, this leaves an opportunity for extracting rents through a gas-release program.
} 
incumbent. Moreover, even if it succeeds in obtaining gas from another market, e.g., a competitive market as in our model, such an entrant is unlikely to cover the market already supplied by the incumbent. Hence, in order for the entrant to have access to gas sources and compete with the incumbent, programs of investment in transport capacity and/or gas-release measures need to be implemented.

A widely used functional form for the transport variable cost function is $C_{T}(K)=\left(a+b K^{\beta}\right) L$ where $L$ is the length of the pipeline. We have normalized $L$ to 1 and approximated the total transport cost function by the increasing convex cost function $C_{T}(K)+F_{T}=\frac{\omega}{2} K^{2}+F_{T}$. An examination of French data has led us to assume that $\omega \in(0.112,0.156)$ and $F_{T}=1.746$. The TPA charge $p_{K}$ was estimated from an example provided by the French transport network managing company GRTgaz for gas that entered France through the Obergailbach point in the Lorraine region and got delivered in the massif central region of Auvergne. This estimate amounted to $€ 0.737 / \mathrm{MWh}^{24}$

\subsection{Simulations}

Let us recapitulate the results of our French-data-based calibration exercise from the previous section. The demand function for natural gas in the regional market dominated by the incumbent is given by $p\left(q_{m}\right)=62-q_{m}$ where quantity is in MWh and price in $€ / M W h$. The (separable) cost function of the incumbent is specified as $C_{I}\left(q_{I}+q_{R}\right)=C_{I}^{I}\left(q_{I}\right)+C_{I}^{R}\left(q_{R}\right)$ where $C_{I}^{I}\left(q_{I}\right)=\theta_{I} q_{I}$ and $C_{I}^{R}\left(q_{R}\right)=$ $\theta_{R} q_{R}$ are such that $\theta_{R}=38.18$ and the discrepancy between the marginal costs $\theta_{I}$ and $\theta_{R}, \Delta$, expressed in $€ /$ MWh, lies in the segment $(7.02,14.46)$. The cost of gas imported from the competitive market, $c$, is equal to $€ 29 / \mathrm{MWh}$ and the cost in euros of transporting $K \mathrm{MWh}$ is given by $C_{T}(K)+F_{T}=\frac{\omega}{2} K^{2}+1.746$, where $\omega \in(0.112,0.156)$. Finally, the transport charge $p_{K}$ is taken to be equal to $€ 0.737 / \mathrm{MWh}$.

Figures 1-4 below displays the results of the comparison of the two scenarios $S_{1}$ and $S_{2}$ along four dimensions, namely, capacity $K$, volume of gas released, $q_{R}$, consumer surplus, $C S$, and social welfare, $W$, for values of $\Delta$ and $\omega$ lying

\footnotetext{
${ }^{24}$ See http://wwww.grtgaz.com.
} 
in respectively the segments $(7.02,14.46)$ and $(0.112,0.156)$.

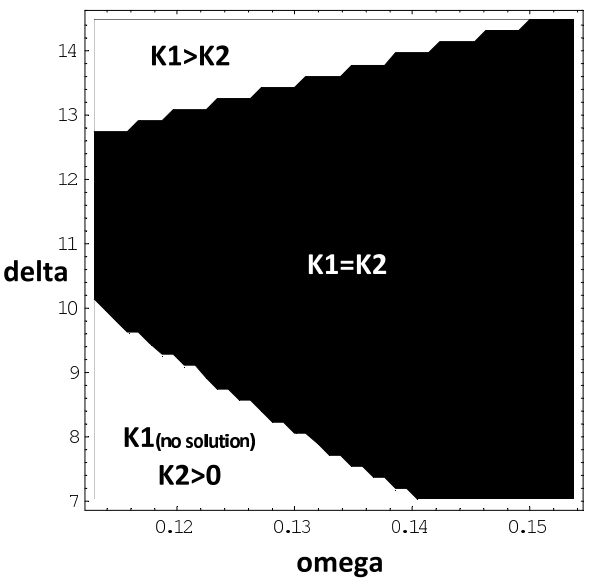

Figure 1: Comparison of $K$

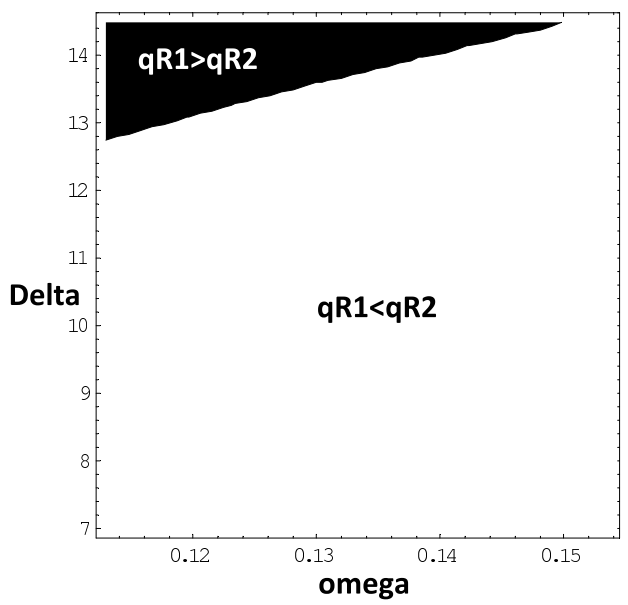

Figure 2: Comparison of $q_{R}$ 


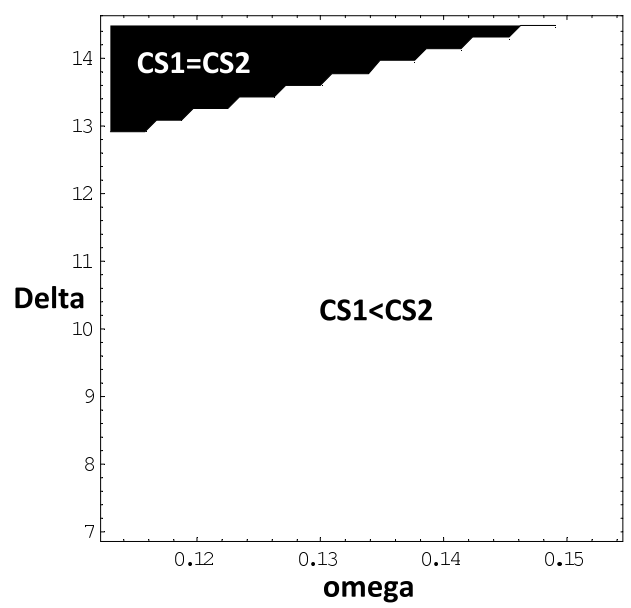

Figure 3: Comparison of $C S$

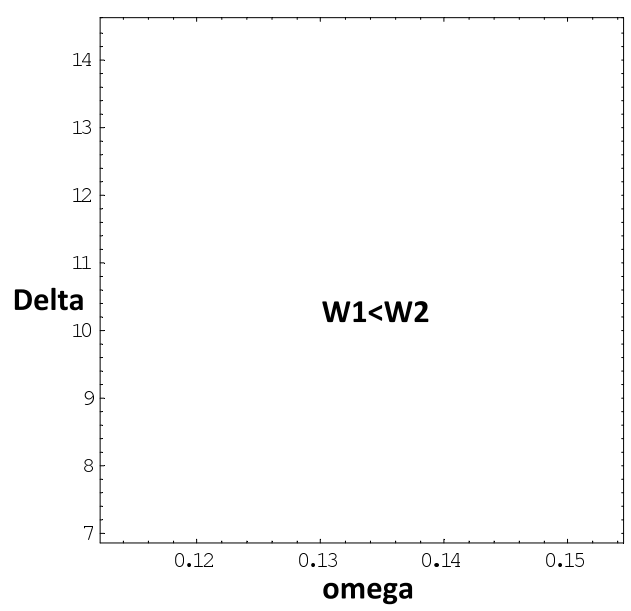

Figure 4: Comparison of $W$

From Figure 1 we see that for low values of $\Delta$ and $\omega$ scenario $S_{1}$ (unregulated gas release-regulated capacity) is not feasible in the sense that equation (15) admits no solution in $K$. For all other regions of the $\Delta-\omega$ space, we see that $K_{1} \geq K_{2}$, i.e., for high $\Delta$ or high $\omega$, optimal capacity is higher when gas release is not regulated (under $S_{1}$ ) than when it is (under $S_{2}$ ). In contrast, Figure 2 shows that, except for high values of $\Delta$, the optimal level of gas released by the incumbent is higher when gas release is regulated (under $S_{2}$ ). Moreover, as 
can be seen from Figures 3 and 4, regulated gas release unambiguously leads to higher consumer surplus and social welfare.

\section{Conclusion}

This paper has been motivated by the recent efforts of governments within the European Union to introduce gas-to-gas competition. Broadly speaking, it is fair to say that Europe has been largely dependent on a few gas suppliers, in particular, Algeria, Russia, and Norway. Moreover, national industries have been historically organized as monopolies that integrated the import, transport, storage, and final distribution activities. This very concentrated structure of the European gas industry has made the liberalization reforms look more like what can be characterized as active asymmetric regulation aimed at establishing a more balanced share of markets.

Two prominent instruments used to achieve such a goal are gas-release measures and capacity investment programs. In this paper, we have proposed a simple model for examining the interaction between these two policies for improving the performance of imperfectly competitive natural gas markets. We have assumed that the gas-release measure is complemented by a program of investment in transport capacity dedicated to the shipping of competitive gas by a marketer at a regulated transport charge. Calibration and simulation techniques have then been used to evaluate the impact of regulating gas release on social welfare. Besides allowing us to highlight some of the economic properties of gas release and capacity investment policies, this exercise brings empirical evidence on the welfare benefits of regulating gas release. Gas release, when regulated, is pro-competitive and yields social welfare benefits indeed.

A few directions for further research need to be explored. A first extension of this work consists in enlarging the set of scenarios to be compared to include actual policy experiences in the EU. This set would include, among others, scenarios in which only gas release is available as an instrument to foster competition (in the spirit of Chaton et al., 2008) and scenarios in which only capacity is available. A comparative analysis would then provide us with a richer information on the interaction between a larger set of regulatory in- 
struments and their efficiency from a policy standpoint. A second direction for further research would be to take into account dynamic effects, in particular, in the contractual relationship between gas producers and gas suppliers. A third direction would be to introduce information problems, in particular, to analyze the social cost of private information of the incumbent on $\Delta$, the discrepancy between the cost of the gas provided by the incumbent to final consumers, $\theta_{I}$, and that of the gas released by the incumbent to the marketer, $\theta_{R}$. Finally, it is would be interesting to introduce price discrimination to account for the heterogeneity of gas consumers. 


\section{References}

Bohi, D. and M. Zimmerman, 1984, "An update on econometric studies of energy demand behavior," Annual Review of Energy, 9:105-154.

Chaton, C., F. Gasmi, M.-L. Guillerminet and J.D. Oviedo, 2008, "Un instrument de court terme pour stimuler la concurrence: Le gas release," Revue Economique, 59(3): 475-486.

Clastres, C. and L. David, 2009, "The impact of asymmetric regulation on surplus and welfare : the case of gas release programs," Opec Energy Review, 33(2): 97-110.

CRE, 2007, Rapport annuel, Partie 3 : Annexes.

—_, 2006, Rapport annuel, Partie 2 : La régulation du marché du gaz naturel.

Cremer, H., Gasmi, F. and J.J. Laffont, 2003, "Access to pipelines in competitive gas markets," Journal of Regulatory Economics, 24(1): 5-33.

Cremer, H. and J.J. Laffont, 2002, "Competition in gas markets," European Economic Review, 46: 928-935.

Dahl, C., 2004, "Energy demand elasticities-Facts and fiction: A survey update," Mimeo Colorado School of Mines Working Paper.

Direction Générale de l'Énergie et du Climat (DGEC)-Institut Français du Pétrole (IFP), 2008, Focus Gaz - Lettre d'information sur les marchés internationaux du gaz naturel, 12 décembre 2008.

Direction Générale de l'Énergie et du Climat (DGEC)-Institut Français du Pétrole (IFP), 2009, Focus Gaz - Lettre d'information sur les marchés internationaux du gaz naturel, 13 fécembre 2009.

Directive of the European Parliament and of the Council Amending Directive 2003/55/EC concerning common rules for the internal market in natural gas, referenced E3643 - COM (2007) 529 final. 
Gasmi, F., Laffont, J.J., and J.D. Oviedo, 2005, "Controlling regional monopolies in the natural gas industry - The complete information case," Mimeo, Toulouse School of Economics (IDEI).

Gasmi, F. and J.D. Oviedo, 2005, "Regulation of regional monopolies in natural gas markets," Mimeo, Toulouse School of Economics (IDEI).

2010, "Investment in transport infrastructure, regulation, and gas-gas competition," Energy Economics, 32(3): $726-736$.

Krichene, N., 2005, "A simultaneous equations model for world crude oil and natural gas markets," IMF Working Paper 05/32.

Liu, G., 2004, "Estimating energy demand elasticities for OECD countries," Statistics Norway Research Department Discussion Paper 373.

Madlener, R., 1996, "Econometric analysis of residential energy demand: A survey," Journal of Energy Literature, 2: 3-32.

Sannarnes, J.G., 2007, "Investment mechanism design and public policy for a natural gas grid," Working Paper 29/07, Institute for Research in Economics and Business Administration, Bergen, Norway.

Tirole, J., 1988, The Theory of Industrial Organization, MIT Press. 